\title{
Intramural oesophageal dissection
}

\author{
J M Hanson, D Neilson, S H Pettit
}

Intramural oesophageal dissection is a rare cause of sudden severe retrosternal pain. It was first recognised by Williams in $1957^{1}$ and since then a further 39 cases have been reported. ${ }^{2-24}$ The injury is intermediate between oesophageal rupture (Boerhaave's syndrome) and a Mallory Weiss tear of the lower oesophagus. All three conditions are caused by a sudden increase in pressure in the lower oesophagus.

Spontaneous rupture of the oesophagus was first recognised by Boerhaave in $1724 .{ }^{25}$ It usually occurs as a result of violent retching or vomiting and typically presents with severe retrosternal pain, surgical emphysema in the neck and mediastinum, and a pleural effusion, which is more common on the left side. Diagnosis is confirmed radiologically by contrast swallow, the contrast leaking into the pleural cavity. Early thoracotomy with suture of the oesophageal defect offers the best chance of survival.

Mallory and Weiss reported upper gastrointestinal haemorrhage in association with vomiting and mucosal laceration of the lower oesophagus in $1929 .{ }^{26}$ This is typically painless and resolves with conservative treatment. Diagnosis is confirmed endoscopically when a mucosal tear is seen in the lower oesophagus.

\section{Presentation}

Intramural oesophageal dissection occurs when a haematoma forms between the mucosal and muscular layers of the oesophagus and then extends in the submucosal plane, stripping off the oesophageal mucosa. Review of the 40 reported cases ${ }^{2-24}$ and one of our own (see below) shows that it is more common in women than men, women in their sixth decade being most commonly affected (fig 1). In $32 \%$ of the 41 cases intramural oesophageal dissection followed an episode of retching or vomiting. In $29 \%$ the injury followed a meal, during which some patients described an impacted food bolus being forcefully swallowed. Other causes were sneezing (two patients), drinking (two), and falling (one). In a quarter of cases the precipitating factor was not recorded. The most common presenting symptoms were sudden, severe retrosternal pain (in $83 \%$ of cases), haematemesis $(71 \%)$, odynophagia $(41 \%)$, and dysphagia $(32 \%)$. Diagnosis was confirmed by barium swallow in 38 of the 41 patients. In $53 \%$ of these barium entered the submucosal haematoma cavity, producing the "mucosal stripe sign"5-a sharply defined lucent linear stripe where the true oesophageal lumen is separated from the submucosal haematoma cavity. In $42 \%$ the oesophageal lumen appeared compressed by the submucosal haematoma. Two patients had both radiological features. One patient had a normal barium swallow and in this case the diagnosis was made at thoracotomy. ${ }^{20}$ Two patients did not undergo barium swallow. ${ }^{618}$ In both cases the diagnosis was confirmed by oesophagoscopy when the submucosal haematoma was seen bulging into the oesophageal lumen.

\section{Prognosis}

Thirty one of these patients $(75 \%)$ recovered fully with conservative treatment. In 26 patients this included fasting and intravenous fluids for 24 hours to 16 days (median seven days); intravenous feeding was used in four cases and prophylactic antibiotics in three. Five patients were allowed liquid diets from the onset of symptoms. One patient died three days after the onset of symptoms while being treated conservatively ${ }^{12}$ but the cause, massive haemorrhage from a duodenal ulcer, was unrelated. Nine patients underwent surgery. Five had an exploratory right thoracotomy ${ }^{79162024}$; in each case the oesophagus was mobilised and found to be intact. All recovered fully. Two patients ${ }^{6}$ underwent laparotomy, during which a tube gastrostomy was inserted and pyloroplasty performed. The aim of this was to decompress the stomach, thereby reducing reflux and the risk of peptic

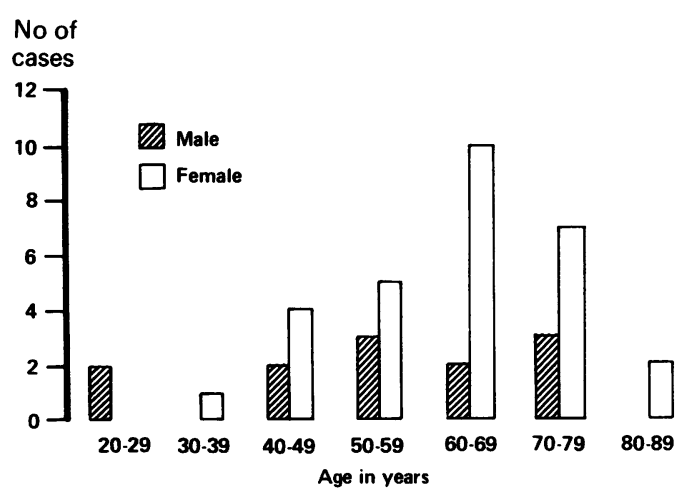

Figure 1 Histogram showing age and sex distribution in 41 cases of intramural oesophageal dissection (40 previously reported and one reported in this article).
Miss J M Hanson, FRCS, Department of Accident an James's University Hospital Leeds LS9 7TF.

Accepted 26 April 1991 
Figure 2 A tube of oesophageal mucosa hanging from the patient's mouth.

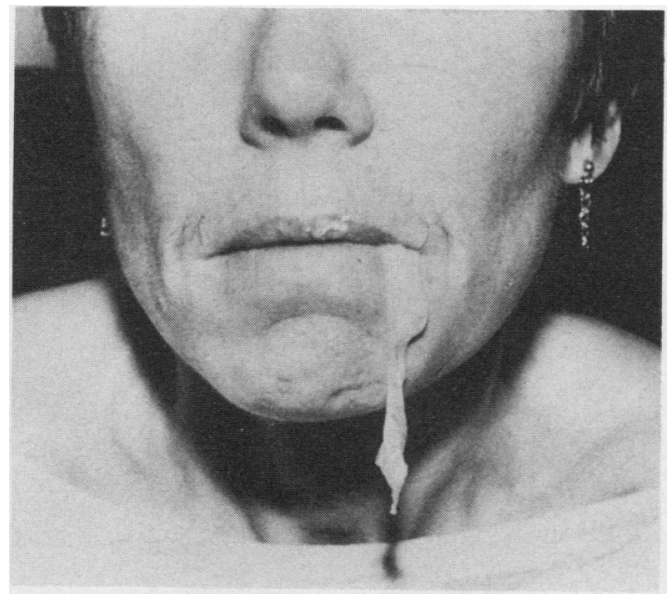

digestion of the oesophagus. Both patients recovered fully. In one patient barium swallow showed blood clot obstructing the mid oesophagus. ${ }^{16}$ Laparotomy was performed and at operation a large tube was

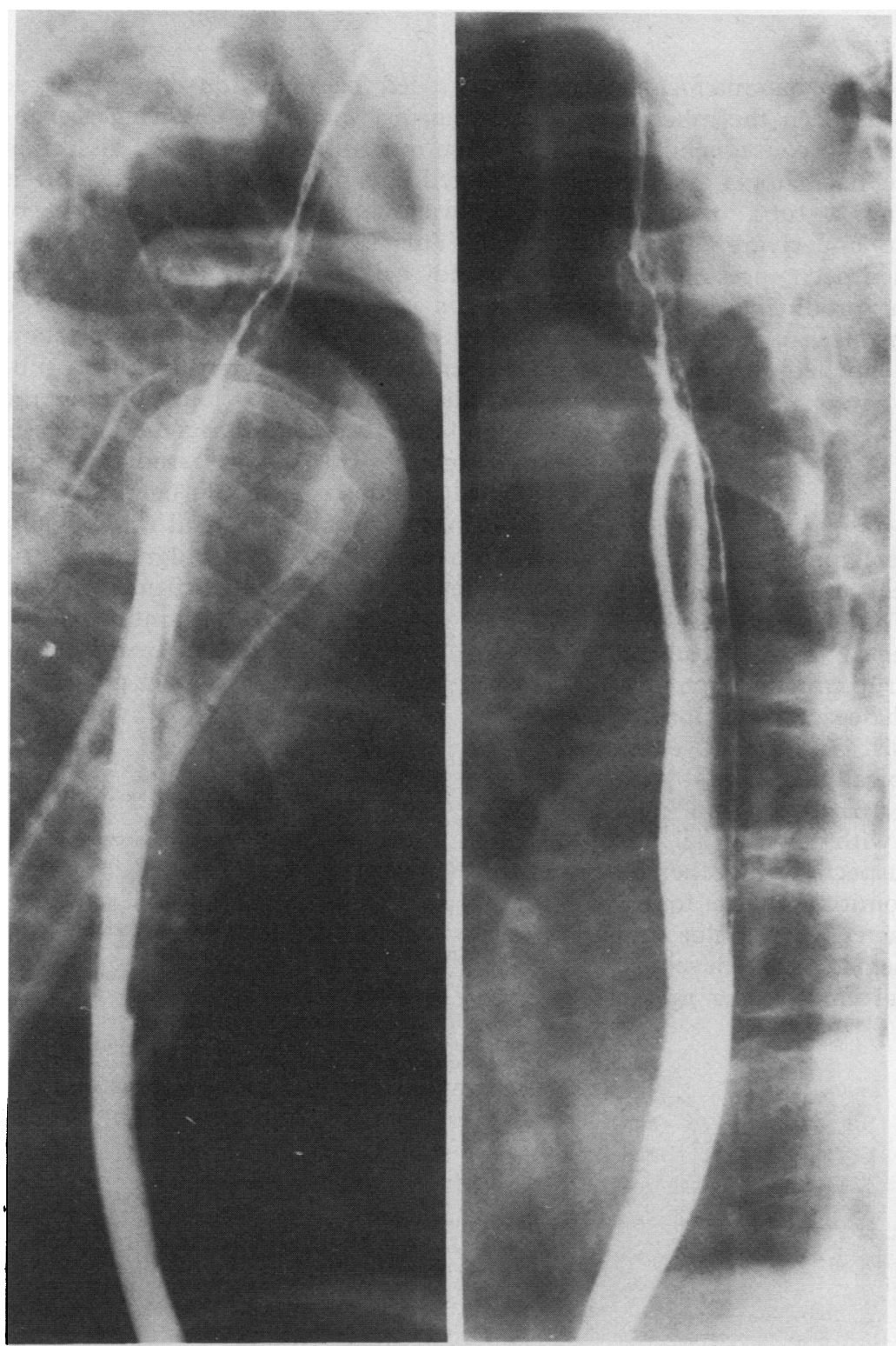

Figure 3 Barium swallow showing oblique and anteroposterior views of the thoracic oesophagus. A thin line of barium appears to lie outside the oesophageal lumen. This appearance is caused by the barium that collects in the haematoma cavity between the dissected oesophageal mucosa and surrounding oesophageal muscle. passed down the oesophagus and into the stomach without difficulty. As this indicated the absence of appreciable oesophageal obstruction no other procedure was undertaken. This patient also recovered fully. None of these eight patients underwent a definitive procedure to repair the oesophagus. The patients may therefore have recovered without surgical intervention. One further patient underwent laparotomy. ${ }^{3}$ A high gastrotomy was performed and the lower oesophagus was palpated from below. Blood clot was present in the oesophageal lumen. An oesophagoscope was passed from above but this unfortunately perforated the oesophagus. Thoracotomy was performed and the oesophageal perforation repaired. The patient developed an infection after surgery and emergency total oesophagectomy was performed eight days later. The patient subsequently died. This is the only death attributable to intramural oesophageal dissection in this series. With hindsight it seems possible that this patient would have survived if treated conservatively from the onset of symptoms.

\section{New case}

A further case of intramural oesophageal dissection is reported here, which documents the mechanisms of injury in this condition as the dissected tube of mucosa was recovered from the patient. A 45 year old wòman developed severe retrosternal pain and a sensation of food sticking while she was hurriedly eating a sandwich. She forced herself to vomit and brought up a small amount of blood and a $15 \mathrm{~cm}$ tube of oesophageal mucosa. This remained attached to the upper oesophagus and was protruding from her mouth (fig 2). She was not shocked and her chest radiograph was normal. A barium swallow examination was performed. Views of the thoracic oesophagus showed a thin line of barium apparently lying outside the oesophageal lumen (fig 3). This appearance, which is diagnostic of intramural oesophageal dissection, ${ }^{5}$ is caused by barium collecting in the haematoma cavity between the dissected oesophageal mucosa and oesophageal muscle. To remove the tube of oesophageal mucosa from the patient's mouth gentle traction was applied, and the mucosa was easily avulsed from its attachment.

Histological examination of the specimen confirmed that it was a complete tube of oesophageal mucosa. The plane of dissection was in the lamina propria just beneath the epithelium (fig 4). For treatment the patient fasted for five days. A liquid diet was then reintroduced uneventfully and she started having solids two days later. Gastroscopy was performed eight weeks later to assess oesophageal healing. The oesophageal mucosa appeared friable in places with contact bleeding but was otherwise intact. It is now 20 months since the injury. Further endoscopic examinations have not been performed as the patient has remained symptom free. The proposed mechanism of injury in this patient 
Figure 4

Photomicrograph of part of the tube of oesophageal mucosa.

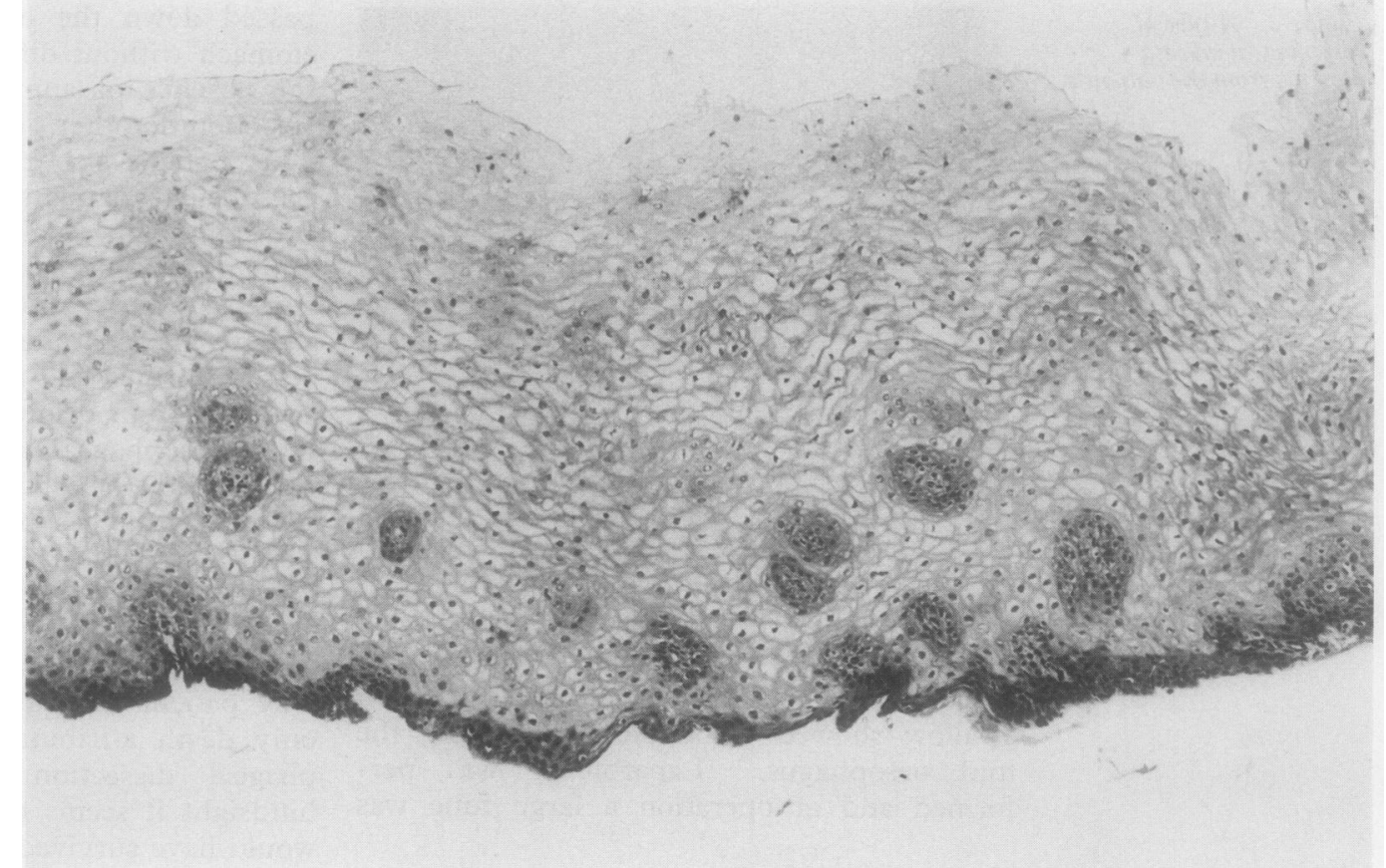

is illustrated in figure 5. A haematoma formed in the mid oesophagus between the mucosal and the muscular layers as a consequence of forced swallowing. The haematoma tracked longitudinally, dissecting a tube of oesophageal mucosa off the underlying muscle. The haematoma was then decompressed into the oesophageal lumen, producing haematemesis. During vomiting part of the tube of dissected mucosa was expelled through the patient's mouth (fig 2).

\section{Diagnosis}

When intramural oesophageal dissection occurs an intramural haematoma forms, which dissects the oesophageal mucosa from the underlying muscle. The haematoma may compress the oesophageal lumen, causing dysphagia, and may rupture through the dissected mucosa into the oesophageal lumen, producing haematemesis. Intramural oesophageal dissection typically presents with sudden, severe retrosternal pain and may initially be confused with myocardial infarction. It should be suspected when there is a history of retching, vomiting, or the forced swallowing of an impacted food bolus and when dysphagia or haematemesis develops. The absence of surgical emphysema in the

Figure 5 Mechanism of injury in the case shown in figures $2-5$.
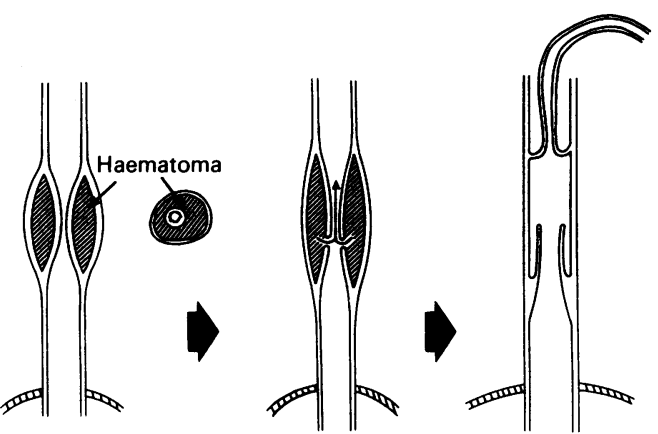

neck and a left basal pleural effusion argue strongly against complete oesophageal rupture. When intramural oesophageal dissection is suspected the best initial investigation is barium swallow, performed as a matter of urgency. This is less traumatic than endoscopy and will determine whether the oesophagus is intact. The diagnosis will be confirmed when oesophageal views show either compression of the lumen by submucosal haematoma or barium entering the haematoma cavity and causing the "mucosal stripe sign." If barium studies prove inconclusive endoscopy should be performed. The diagnosis will be confirmed when a submucosal haematoma is seen bulging into the reports $^{1-24}$ suggests that intramural oesophageal dissection should be treated conservatively and that the prognosis is good.

1 Williams B. Oesophageal laceration following remote trauma Br J Radiol 1957;30:666-8.

2 Benjamin B, Hanks TI. Submucosal dissection of the finding. J Laryngol Otol 1965;79:1032-8.

3 Thompson NW, Ernst CB, Fry WJ. The spectrum of emetogenic injury to the esophagus and stomach. $\mathrm{Am} \mathrm{J}$ Surg 1967;113:13-26.

4 Marks IN, Keet AD. Intramural rupture of the oesophagus. Br Med J 1968;iii:536-7.

5 Lowman RM, Goldman R, Stern $H$. The roentgen aspects of intramural dissection of the oesophagus. Radiology 1969; 93:1329-31.

6 Talley NA, Nicks R. Spontaneous submucosal haematoma of the oesophagus: "oesophageal apoplexy." Med J Aust 1969;ii: 146-50.

7 Borrie J Sheat J. Spontaneous intramural oesophageal perforation. Thorax 1970;25:294-300.

8 Joffe N, Millan VG. Postemetic dissecting intramural haematoma of the oesophagus. Radiology 1970;95:379-80.

9 Kelley DL, Neugebauer MK, Fosburg RG. Spontaneous intramural oesophageal perforation. J Thorac Cardiovasc Surg 1972;63:504-8.

0 Smith G, Brunnen PL, Gillanders LA, Teo HS. Oesophageal apoplexy. Lancet 1974;i:390-2.

1 McMyn JK. Spontaneous intramural oesophageal perforation. Aust Radiol 1977;21:234-40.

12 Atefi D, Horney JT, Eaton SB, Shulman M, Whaley W, Galambos JT. Spontaneous intramural hematoma of oesophagus. Gastrointest Endosc 1978;24:172-4. oesophageal lumen. Evidence from previous oesophagus due to haemorrhage: a new radiographic 
13 Frater von LL, Imre J, Horvath OP, Rozsa Z. Intramurale ösophagusperforationen. Fortschr Röntgenstr 1978;129: 708-12.

14 Smart RF, Stone AR. Intramural oesophageal haematoma complicating anticoagulant therapy. $N Z$ Med J 1978; 87:176-7.

15 Barone JE, Robilotti JG, Comer JV. Conservative treatment of spontaneous intramural perforation (or intramural hematoma) of the esophagus. Am J Gastroenterol 1980; hematoma)

16 Kerr WF. Spontaneous intramural rupture and intramura haematoma of the oesophagus. Thorax 1980;35:890-7.

17 Morritt GN, Walbaum PR. Spontaneous dissection of the oesophagus. Thorax 1980;35:898-900.

18 Spiller RC, Catto JVF, Kane SP. Spontaneous dissecting intramural haematoma of the oesophagus: a rare cause of haematemesis and dysphagia. Endoscopy 1981;13:128-30.

haematemesis and dysphagia. Endoscopy 1981;13:128-30.
19 Berliner L, Redmond P, Pachter HL. Spontaneous intramural perforation of the esophagus: case report and review of the literature. Am J Gastroenterol 1982;77:355-7.

20 Biagi G, Cappelli G, Propersi L, Grossi A. Spontaneous intramural haematoma of the oesophagus. Thorax 1983; 38:394-5.

21 Natsuda Y, Kuwano H, Ezaki T, Sugimachi K, Inokuchi K. Spontaneous submucosal dissection of the esophagus. Jap J Surg 1983;13:354-7.

22 Lamont G, Elliott S, Morris DL. Spontaneous intramural oesophageal dissection. Thorax 1985;40:558-9.

23 Hooper TL, Gholkar J, Smith SR, Manns JJ, Moussalli H. Recurrent submucosal dissection of the oesophagus in association with achalasia. Postgrad Med $J$ 1986;62:955-6.

24 Pellicano A, Watier A, Gentile J. Spontaneous doublebarrelled esophagus. J Clin Gastroenterology 1987;9: 149-54.

25 Derbes VJ, Mitchell RE. Hermann Boerhaave's “Atrocis, nec descripti prius, morbi historia": the first translation (from original Latin, 1724) of the classic case report of rupture of the esophagus, with annotations. Bull Med Lib Ass 1955;43:217-40.

26 Mallory GK, Weiss S. Haemorrhages from lacerations of the cardiac orifice of the stomach due to vomiting. $\mathrm{Am} \mathrm{J} \mathrm{Med}$ Sci 1929;178:506-15. 